\title{
Balance Is a Fallacy: Striving for and Supporting a Life with Integrity
}

\author{
Renée A. Cramer, Drake University \\ Nikol G. Alexander-Floyd, Rutgers University, New Brunswick \\ Taneisha Means, Vassar College
}

\section{W}

e are three women political scientists. Two of us are women of color (black women), two are mothers, one has a chronic illness; we all identify as first-generation college students. We care about our students and about our research; we strive for emotional, physical, and spiritual well-being. We know that the expectation for managing our complex lives is to find work-life balance. Work-life balance is a gold standard: something employers are meant to help us achieve and something for which we are supposed to strive. We have even come to expect it for ourselves.

However, our auto-ethnographic and intersectional analysis of our experiences as successful professional women-coupled with research on women in politics, in the workforce, and in the academy-shows us that balance is an inappropriate and even dangerous metaphor (Crenshaw 1990-1991). Balance insinuates that there is some kind of magical moment when everything falls into place and our personal and social lives are coequal with our professional lives. It gives the impression that there is some stability or equilibrium between work and personal life-something we have not found to be true. The myth of balance-and the expectation that we strive for it-reinforces unreasonable standards that are rooted in the neoliberal concept of the ideal worker. This is an ideal we cannot, and will not, embody. We reject the metaphor of balance because it places responsibility on workers rather than on institutions; it does not address structural injustice and root causes of harm. We offer here an assessment of balance that accounts for social location in the production of institutional norms, dynamics, and constraints in relationship to individuals and communities.

The ideal worker in the academy is one who has a trajectory that seemingly is unimpeded by the demands of everyday life. This person has their instrumental activities of daily living-paying bills, doing laundry, and caring for othersmagically taken care of. We think of this worker most often as an individual male or someone who is relatively independent and not set in community. The ideal worker is always available for work and for production. There is no room in that model for multiple responsibilities, for the vicissitudes of life (Hampson 2017).

Early in her career, one of us experienced the untimely death of her husband, after being married for only a little more than a year. Nothing eclipsed that moment in that year, but she experienced a steady stream of additional complications. A few months later, her programmatic home was moved to a different department to assuage conflict among leadership. The book she had been shopping, which was based on her dissertation, was not yet under contract, and she had to write a second book-in many ways quite essentially different from that project-while on the tenure track.

She assumed that she would handle the unfolding of these personal and professional crises as she had beforethat is, by pressing on. She expected that she would be a black superwoman (Wallace 1994/1978). With gratitude, she recalls a colleague, a self-described white liberation feminist, who suggested that she apply for a year's extension on her tenure clock. She resisted and had to be convinced but took the extension allowed by institutional policy, which enabled her to have space for if not relief from her grieving. We all know that gaps in a C.V. are only ever read problematically. There is no space on that document to provide explanatory narratives about our widowhood; our caregiving of elders, partners, and children; our leaving bad relationships; our health challenges-even when these are more important than almost anything else to list.

The black superwoman is a creation of economic and political conditions, a mindset and practice borne out of both oppression and resistance to it. Women-of-color scholars have long been attuned to the expectations of heroic triumph over challenging circumstances and have resisted such demands. As Lorde (1988) famously said: "[c]aring for myself is not self-indulgence, it is self-preservation, and that is an act of political warfare." In this sociopolitical moment, the pull of superheroism seems stronger than ever and in especially prominent circulation is a discourse that promotes a turn to the self in dealing with what are public and social issues.

Neither is the ideal worker imagined as being wracked with survivor's guilt. However, such guilt is very real for those of us who have left difficult family situations, feeling as though we have abandoned siblings and parents to build a successful life. Such guilt arises as sister friends in the academy share the ways that they have suffered. What happens when-despite our and their best efforts-these women are pushed out of the workplace, leaving not on their own terms but rather forced to make a change of life that is read as a personal as opposed 
to an institutional failure? One of our black female professor friends told us that if she returned to her place of employment, she would die. Another friend, who was derisively described as having had a nervous breakdown, out-spiraled into a totally new career as an entrepreneur. One institution reportedly had those who said that black women could not succeed there, so they started hiring Asian women instead. We experience isolation and hostility in academic life, even as
Neoliberalism's devolution of responsibility for the social good from the collective/nation to smaller, related entities (e.g., state and local governments) recedes responsibility even further, to the self (Alexander-Floyd 2012). Neoliberalism extends into every element of our daily lives, changing social needs into personal deficits to be remedied through accumulation and self-fashioning (Gill and Scharff 2011; Tasker and Negra 2007). In the academy, we are asked to count, record,

\section{The myth of balance-and the expectation that we strive for it-reinforces unreasonable standards that are rooted in the neoliberal concept of the ideal worker.}

students and coworkers surround us. This lack of intimacy is not a personal problem but rather a social and political one. As Pickens (2012) noted: "Anne DuCille once said......that her lack of intimacy was not just her problem, but also ours. Her logic was that a lack of intimate relationships between people speaks volumes about the social environments that deprive people of those relationships." Our experiences demonstrate that the loneliness and isolation of the academy is not a singular problem or failure; it is a collective problem.

Seeking balance-and feeling like failures in its pursuitalso is closely tied to our struggles with the Imposter Syndrome (Clance and Imes 1978; Gluckman 2017; Parkman 2016). Because of the continuing exclusion of marginalized groups, including people of color and white women, we-as members of those groups-often feel like we are imposters. Daily, we juggle perceived failures and mistakes that make us question our priorities and next steps. We feel like we are faking our success or are haphazard winners in the lottery of academic life, both undeserving of the success we have achieved and at risk of losing it all when someone wises up to our charade. The Imposter Syndrome has driven us to work in ways detrimental to our emotional and physical health, our personal lives, and our relationships (Rockquemore and Laszloffy 2008). specify, and justify our productivity. Our day-to-day lives become hidden from view while simultaneously the locus of disciplinary concern.

Our identities as mothers, daughters, sisters, aunts, wives, widows, and friends remain unrecognized by practices within the academy. One of us recalls going to the hospital to give birth and a supervisor demanding, "I'll need you to complete a couple of tables next week," adding, "I know you'll be in the hospital...you'll have plenty of time when your baby is in the nursery." Another of us remembers a death in the family that took her away from the classroom; a supervisor noted that it was unfortunate that the funeral fell on such a "good day for class discussion." A member of her graduate cohort told one of us that she had a reputation as "under-placed" because she had "chosen to value her family more than her career." Another one of us recalls being home after a long day at work; she was cooking dinner when the call came that a departmental meeting had been scheduled for 5:30 that evening.

The message is that we must always be "on" and ready to drop everything for the job; if we choose differently, we are not choosing success. The ideal worker-mother would nurse a baby while typing up tables, would have emergency childcare at the ready for the last-minute meeting, and would Skype her class after the funeral to talk about the readings.

\section{The ideal worker-mother would nurse a baby while typing up tables, would have emergency childcare at the ready for the last-minute meeting, and would Skype her class after the funeral to talk about the readings. Academic culture rewards "going the extra mile" in these ways. Balance here simply means not falling off the tightrope that we are walking while professing while black, professing while women-professing while human.}

Paradoxically, the Peter Principle Effect (PPE; a corollary of the Twice as Hard Imperative) also is significant. With PPE, one experiences a growing and sometimes persistent frustration that white men-and, in some cases, white women-are able to attain degrees, promotions, and positions (even the presidency) for which they are under- or even unqualified, whereas women of color must far exceed standards of excellence and requirements for each opportunity.
Academic culture rewards "going the extra mile" in these ways. Balance here simply means not falling off the tightrope that we are walking while professing while black, professing while women-professing while human.

\section{INSTITUTIONAL INTEGRITY}

Although we are critical of the idea of work-life balance, we must grapple with the concept. Asserting counter-narratives 
and imaging alternatives is, for us, a matter of survival. We suggest that workers and institutions strive instead for integrity, to act in consonance with our values. This means engaging in self-care-not neoliberal self-discipline. For self-care, we engage in religious observance, therapy, yoga, exercise, sports, hobbies, and friendships in which we desire to engage. We attend workshops like the one that enabled us to coauthor, engaging in vulnerable and powerful conversation. We read books and articles that help us understand our positionality. We find and create spaces that affirm us-such as the National Conference of Black Political Scientists, which will celebrate its fiftieth anniversary in 2019, and the Association for the Study of Black Women and Politics.

One coauthor's understanding of integrity draws on yoga, which counsels that it is better to do a smaller approximation of a pose than to find its fullest expression. It teaches a way to say no and leave a pose (a relationship, a workplace, a set of expectations) instead of abandoning our integrity. Another coauthor's understanding of integrity, drawn from her Christian faith, grounds the goal of life-including one's career-in a higher purpose of serving God and humanity. Integrity, in this context, also means avoiding making an idol of work or relationships, including relationships with coworkers and peers. Certainly, we could balance numerous commitments, but we would do justice to none.

However, "having integrity" cannot become a recipe for responsibilization (Trnka and Trundle 2014), in which individuals gird themselves for battle against institutional problems. What would the academy look like if we valued people who made integral decisions-leaving the meeting, saying no to a commitment, taking on those projects that hew most closely to their values and mission-rather than those who seek an impossible ideal of a "balanced" life? What would the academy look like if institutions enabled our striving for integrity, understood as fluid, nuanced, and intimate? We seek-indeed, demand-institutions that act with integrity toward their workers and that consider structural intersectionality to offer suggestions that shift the locus of attention to cultural, material, and institutional change.

Institutions that have integrity will evince thoughtfulness about practices and procedures that impact the non-work life of their faculty. They will ask questions such as when and held at one of our institutions that sometimes include ice cream and popcorn.

Institutions with integrity will have a culture of transparency, especially around standards, and clear, written, and objective guidelines and sets of criteria for evaluation, promotion, and tenure. Institutions, including the discipline of political science, should clearly demonstrate that they value-as legitimate and important-research conducted on marginalized communities and under-researched topics, especially research that uses methodologies outside of disciplinary traditions. These practices and considerations mitigate against biases, especially around identity, in decision-making processes. Institutional clarity supports faculty in their writing and research as do memberships in organizations such as the National Center for Faculty Diversity and Development and Easton's Nook (New Jersey), equipping faculty with the tools necessary to thrive and meet established expectations.

Institutions with integrity will foster a discourse that centers on self-care, boundaries, and the whole person rather than "productivity." Their academic leaders will facilitate collegial cultures of sharing and collaboration. They will provide formalized and structured programs for sponsorship and mentoring at all levels-for junior and senior scholars as well as administrators.

These institutions will have honest conversations around the invisible service done by faculty belonging to marginalized groups (Flaherty 2018; Gutierrez y Muhs et. al. 2012; Moore 2017). They will take active steps to reduce tokenism by increasing diversity of the faculty so that visible minorities are not overwhelmed with service requests. Instead, they will have meaningful experiences with service related to their expertise and interests, not reliant on their racial or gender identity or sexual orientation. Institutions will field surveys that allow them to keep track of who is doing how much and what service. They will use that information to assign service responsibilities more equitably and thoughtfully, ensuring fairness by rotating the assignments across the faculty instead of relying on volunteers (Babcock, Recalde, and Vesterlund 2018).

Our lived experiences bring us to make these institutional recommendations that we believe place some of the onus on

\section{Our lived experiences bring us to make these institutional recommendations that we believe place some of the onus on institutions for creating and fostering spaces that respect and value the individuals working within them and not only their labor.}

where do we meet and how might those meeting times impact responsibilities outside of teaching-research-service? They will establish a culture around technology and availabilityincluding responding to emails and being available for students and colleagues-that respects our multiple life responsibilities and ensures that we are not always chained to work (Wilk 2014). These institutions will have institution-sponsored family- and kid-friendly events-such as the faculty socials institutions for creating and fostering spaces that respect and value the individuals working within them and not only their labor. If implemented, our recommendations can transform institutions into organizations that simultaneously help us to navigate the academy and challenge neoliberalism's call for competition, privatization, proliferation, and commercialization (Dugas et al. 2018). Richard Carp (2001, 86-7), referencing Lefbevre's response to Merleau-Ponty, wrote: 
We behave "[a]s if bread and wine and labor were in themselves less grave and sacred things than history books" $(1964,4)$. Yet if I am to live well, it will be as a man, born in 1949, raised in the United States of America, with all the specific contexts by which I am informed and to which I am beholden; if you are to live well, it will be in and as the specific bodily circumstances that make up the very life you are living well. What we need are mindful bodies and embodied minds-bread, wine, labor, what is lived are grave and sacred things.

We have shared defining moments from our lives in academia. This is not to say that our experiences have been awful. Our intent is to illustrate our analysis with examples that explain why-at several points in our careers-we have questioned whether we could ever be successful and satisfied in academia. We hope you understand that what we share in this article-bread, wine, labor, what we have lived-are grave, and they are sacred.

\section{REF ER E N C E S}

Alexander-Floyd, Nikol G. 2012. "'But I Voted for Obama': Melodrama and Post Civil Rights, Post-Feminist Ideology in Grey's Anatomy, Crash, and Barack Obama's 2008 Presidential Campaign." National Political Science Review 13: 23-39.

Babcock, Linda, Maria P. Recalde, and Lise Vesterlund. 2018. "Why Women Volunteer for Tasks That Don't Lead to Promotions.” Harvard Business Review. Available at https://hbr.org/2018/o7/why-women-volunteer-fortasks-that-dont-lead-to-promotions.

Carp, Richard. 2001. "Integrative Praxes: Learning from Multiple Knowledge Formations." Issues in Integrative Studies 19: 71-121.

Clance, Pauline R., and Suzanne A. Imes. 1978. "The Imposter Phenomenon in High Achieving Women: Dynamics and Therapeutic Intervention." Psychotherapy: Theory, Research \& Practice 15 (3): 241-9.

Crenshaw, Kimberle. 1990-1991. "Mapping the Margins: Intersectionality, Identity Politics, and Violence Against Women of Color." Stanford Law Review 43: 1241-99.
Dugas, Daryl, Kelly H. Summers, Lindsay N. Harris, and Amy E. Stich. 2018. "Shrinking Budgets, Growing Demands: Neoliberalism and Academic Identity Tension at Regional Public Universities." American Educational Research Association Open 4 (1): 1-14.

Flaherty, Colleen. 2018. "Dancing Backwards in High Heels." Inside Higher Ed, January 10.

Gill, Rosalind, and Christina Scharff. 2011. New Femininities: Postfeminism, Neoliberalism, and Subjectivity. London: Palgrave Macmillan.

Gluckman, Nell. 2017. "How a Dean Got over Imposter Syndrome-and Thinks You Can, Too." Chronicle of Higher Education, November 26.

Gutierrez y Muhs, Gabriella, Yolanda Flores Niemann, Carmen G. Gonzalez, and Angela P. Harris (eds.). 2012. Presumed Incompetent: The Intersections of Race and Class for Women in Academia. Boulder: University Press of Colorado.

Hampson, Sarah Cote. 2017. The Balance Gap: Working Mothers and the Limits of the Law. Stanford, CA: Stanford University Press.

Lorde, Audre. 1988. A Burst of Light. Ithaca, NY: Firebrand Books.

Moore, Mignon R. 2017. "Women of Color in the Academy: Navigating Multiple Intersections and Multiple Hierarchies." Social Problems 64: 200-205.

Parkman, Anna. 2016. "The Imposter Phenomenon in Higher Education: Incidence and Impact." Journal of Higher Education Theory and Practice 16 (1): 51-6o.

Pickens, Therí A. 2012. "My Body Is Your Problem (Not Mine)." Available at www.culturalfront.org/2012/o8/my-body-is-your-problem-not-mine. html.

Rockquemore, Kerry, and Tracey A. Laszloffy. 2008. The Black Academic's Guide to Winning Tenure-Without Losing Your Soul. Boulder, CO: Lynne Rienner Publishers.

Tasker, Yvonne, and Diane Negra (eds.). 2007. Interrogating Postfeminism: Gender and the Politics of Popular Culture. Durham, NC: Duke University Press.

Trnka, Susanna, and Catherine Trundle. 2014. "Competing Responsibilities: Moving Beyond Neoliberal Responsibilization." Anthropological Forum 24 (2): 136-53.

Wallace, Michelle. 1994/1978. Black Macho and the Myth of the Superwoman. New York: The Dial Press, 1978. Reprint, with new introduction and bibliography, New York: Verso Press, 1994.

Wilk, Kelly E. 2014. "Work-Life Balance Also Challenges Administrators." Women in Higher Education 22 (10): 20-21. 